NASA

Technical Memorandum 102349
AVSCOM

Technical Memorandum 89-C-006

\title{
Dynamic Analysis of Geared Rotors by Finite Elements
}

Ahmet Kahraman, H. Nevzat Ozguven, and Donald R. Houser

The Ohio State University

Columbus, Ohio

and

James J. Zakrajsek

Lewis Research Center

Cleveland, Ohio

Fo

January 1990

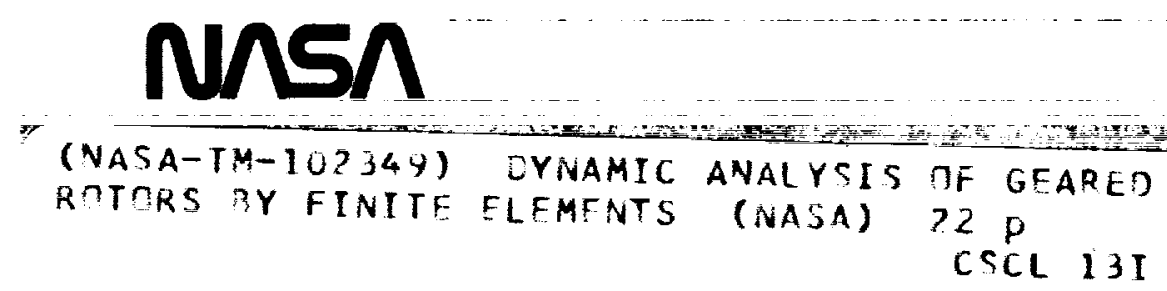





\title{
DYNAMIC ANALYSIS OF GEARED ROTORS BY FINITE ELEMENTS
}

\author{
Ahmet Kahraman, H. Nevzat Ozguven, Donald R. Houser \\ Gear Dynamics and Gear Nolse Research Laboratory \\ Department of Mechanical Engineering \\ The Ohio State University \\ Columbus, Ohio \\ and \\ James Zakrajsek \\ National Aeronautics and Space Administration \\ Lewis Research Center \\ Cleveland, Ohio
}

\section{SUMMARY}

A finite-element model of a geared rotor system on flexible bearings has been developed. The model includes the rotary inertia of shaft elements, the axial loading on shafts, flexibility and damping of bearings, material damping of shafts and the stiffness and the damping of gear mesh. The coupling between the torsional and transverse vibrations of gears were considered in the model. A constant mesh stiffness was assumed. The analysis procedure can be used for forced vibration analysis of geared rotors by calculating the critical speeds and determining the response of any point on the shaft to mass unbalances, geometric eccentricities of gears and displacement transmission error excitation at the mesh point. The dynamic mesh forces due to these excitations can also be calculated. The model has been applied to several systems for the demonstration of its accuracy and for studying the effect of bearing compliances on system dynamics.

\section{INTRODUCTION}

Even though there have been numerous studies on both rotor dynamics and gear dynamics, the studies on geared rotor dynamics have been rather recent. The study of the dynamic behavior of geared rotor systems usually requires that torsional and transverse vibration modes be coupled in the model, a problem not present for studies of for rotors without gears.

For rotor dynamics studies, the finite-element method seems to be a highly efficient modeling method. An early finite-element modeling method (Nelson and McVaugh, 1976) used a Rayleigh beam finite-element, which included the effects of translational and rotary inertia, gyroscopic moments, and axial load. Zorzi and Nelson (1977) generalized the Nelson and McVaugh study to include internal damping. Later. Nelson (1980) developed a Timoshenko beam by adding shear deformation to his earlier work. The Timoshenko model was extended by Ozguven and Ozkan (1983) to include effects such as transverse and rotary inertia, gyroscopic moments, axial load, internal hysteretic, viscous damping, and shear deformations in a single model. None of these models can handle geared rotor systems, although they are capable of determining the dynamic behavior of rotors consisting of shafts supported at several points and carrying rigid disks at several locations. 
Gear dynamics studies, on the other hand, have usually neglected the lateral vibrations of the shafts and bearings and have typically represented the system with a torsional model. Although neglecting lateral vibrations might provide a good approximation for systems having shafts with small compliances, the dynamic coupling between the transverse and torsional vibrations due to the gear mesh affects the system behavior considerably when the shafts have high compliances (Mitchell and Mellen, 1975). This fact lead investigators to the include lateral vibrations of the shafts and bearings in their models. Lund (1978) included influence coefficients at each gear mesh by using the Holzer method for torsional vibrations and the Myklestad-Prohl method for lateral vibrations, thus, obtaining critical speeds and a forced vibration response.

Early geared rotor dynamics models concentrated on the effects of mass imbalance and eccentricity of the gear on the shaft, virtually neglecting the actual dynamics of the gear mesh. Hamad and Selreg (1980) studied the whirling of geared rotor systems supported on hydrodynamic bearings. Torsional vibrations were not considered in this model and the shaft of the gear was assumed to be rigid. Iida, et al. (1980), who considered the same problem, by assuming one of the shafts to be rigid and neglecting the compllance of the gear mesh obtained a three-degree-of-freedom model that determined the first three vibration modes and the forced vibration response due to the unbalance and the geometric eccentricity of one of the gears. They al so showed that their theoretical results confirmed experimental measurements. Later, Ilda, et al. (1984, 1985, 1986) applied the ir model to a larger system consisting of three shafts coupled by two gear meshes.

Haglwara, Ilda, and Kikuchi (1981) developed a simple model that included the transverse flexiblitities of the shafts by using discrete stiffness values that took the damping and compllances of the journal bearings into account and that assumed the mesh stiffness to be constant. With thelr model they studied the forced response of geared shafts due to unbalances and runout errors.

Some of the studies used the transfer matrix method to couple the gear mesh dynamic with system dynamics. Daws (1979) developed a three-dimensional model that considered mesh stiffness as a time-varying, three-dimensional tensor. He included the force coupling due the interaction of gear deflection and time varying stiffness, but he neglected the dynamlc coupling. As a continuation of the Daws study. Mitchell and David (1985) showed that dynamic coupling terms dominate the dynamic behavior of the system. Another model in which the transfer matrix method was used is the model of Iwatsubo, Aril, and Kawa $i$ (1984a) in which the forced response due to only mass unbalance was calculated for a constant mesh stiffness. Later, they (1984b) included the effects of periodic variation of mesh stiffness and proflle errors of both gears.

Other studies used lumped mass and finite-element methods to couple the lateral and torsional dynamics typical of geared rotor systems. Neriya, Bhat, and Sankar (1984) extended the model of I ida et al. (1980) by representing a single gear by a two-mass, two-spring, two-damper system which used a constant mesh stiffness. The gear shafts were assumed to be massless, and equivalent values for the lateral and torsional stiffnesses of shafts were used to obtain a discrete model. As a continuation of this study, Neriya, et al. (1985) used the finite-element method to find the dynamic behavior of geared rotors. They a) so found the forced vibration response of the system due to mass unbalances 
and runout errors of the gears by using modal summation. Bagci and Rajavenkateswaran (1987) used a spatial finite line-element technique to perform mode shape and frequency analys is of coupled torsional, flexural, and longitudinal vibratory systems with special application to multicylinder engines. They concluded that coupled torsional and flexural modal analysis is the best procedure to find natural frequencies and corresponding mode shapes.

An extensive survey of mathematical models used in gear dynamics analyses is given in a recent paper by Ozguven and Houser (1988a).

The major goal of this study was to develop a finite-element model for the dynamic analysis of geared rotor systems and to study the effect of bearing flexibility, which is usually neglected in simpler gear dynamics models, on the dynamics of the system. The formulation of rotor elements, except for gears, used the rotor dynamics program ROT-VIB, which was developed by Ozguven and Ozkan (1983) and Ozkan (1983). However, because of the coupling between torsional and transverse vibration modes, a torsional degree of freedom has been added to the formulation, and some special features of ROT-VIB have been omitted.

SYMBOL LIST

[C] damping matrix of the system

$C_{x x}, C_{y y}$ bearing damping coefficients in the $x$ and $y$ directions, respectively

$c_{m} \quad$ mesh damping coefficient

$c_{s} \quad$ modal damping value of $s^{\text {th }}$ mode

$d_{1}, d_{2}$ diameters of driving and driven shafts, respectively

$E, G$ modulus of elasticity and shear modulus, respectively

$e_{g}, e_{p} \quad$ geometric eccentricities of driven and driving gears, respectively

et amplitude of the harmonic excitation

Fs average value of force transmitted (static load)

$\left\{F_{t}\right\} \quad$ total force vector of the system

$I_{g}, I_{p}$ mass moment of inertias of driven and driving gears, respectively

i imaginary number

$J_{d}, J_{m} \quad$ mass moment of inertias of load and motor, respectively

$K_{t c l}$ torsional compliance of the flexible coupling

$k_{m} \quad$ mesh stiffness coefficient

$k_{x x}, k_{y y}$ bearing stiffness values 
$L_{1}, L_{2}$ lengths of driving and driven shafts, respectively

$\mathrm{m}_{\mathrm{g}}, \mathrm{m}_{\mathrm{p}}$ masses of driven and driving gears, respectively

$\mathrm{N}_{\mathrm{p}}$ tooth number of driving gear

\{q\} total response of the system

$r_{g}, r_{p}$ base circle radil of driven and driving gears, respectively

t $\quad$ time

$U_{g}, U_{p} \quad$ mass unbalances of driven and driving gears, respectively

$x g, x p$ coordinates perpendicular to the pressure line at the centers of the driven and driving gears, respectively

$y_{g}, y_{p} \quad$ coordinates in the direction of the pressure line at the centers of the driven and driving gears, respectively

$\theta_{1}, \theta_{2}$ total angular rotations of driving and driven gears, respectively $\theta_{p}, \theta_{g} \quad$ fluctuating parts of $\theta_{1}$ and $\theta_{2}$, respectively

[\$] modal matrix

$\left[\Phi^{5}\right] \quad s^{\text {th }}$ normallzed elgenvector

$\omega_{p}, \omega_{g} \quad$ rotational speeds of driving and driven shafts, respectively $\omega_{r} \quad r^{\text {th }}$ natural frequency

\section{THEORY}

A typical geared rotor system, as shown in figure 1 , consists of a motor connected to one of the shafts by a coupling, a load at the other end of the other shaft, and a gear pair which couples the shafts. Shafts are supported at several locations by bearings. Hence, a geared rotor system consists of the following elements: (1) shafts, (2) rigld disks, (3) flexible bearings, and (4) gears. When two shafts are not coupled, each gear can be modeled as a rigid disk. However, when they are in mesh, these rigid disks are connected by a spring-damper element representing the mesh stiffiness and damping.

For the formulation of the first three elements listed above, the existing program ROT-VIB, (Ozguven and Ozkan, 1983) was used. ROT-VIB is a general-purpose rotor dynamics program that calculates whirl speeds, corresponding mode shapes, and the unbalance response of shaft, rigid-disk, bearing systems by including the effects of rotary and transverse inertia, shear deformations, internal hysteretic and viscous damping, axial load, and gyroscopic moments. In ROT-VIB the classical linearlzed model with elght 
spring and damping coefficients is used for modeling bearings, and finite elements with four degrees of freedom at each node (excluding axial motion and torsional rotation) are employed for the shaft elements.

In the present analysis the formulation used in ROT-VIB for the se elements was modifled. First, in order to avold nonsymmetric system matrices which result in a complex elgenvalue problem, the gyroscoplc moment effect was ignored and internal damping of the shaft was only included in the damping matrix. Second, the gear mesh causes coupling between the torsional and transverse vibrations of the system, which makes it necessary to include the torsional degree of freedom. Therefore, the mass and stiffness matrices of the system, which are taken from ROT-VIB, have been expanded in this study to include the torsional motion of the shafts. Hence, five degrees of freedom have been defined at each node with only axial motion being excluded. This motion, which would be important for helical gears, could easily be included in later analyses.

\section{Gear Mesh Formulation}

A typical gear mesh can be represented by a pair of rigid disks connected by a spring and a damper along the pressure line which is tangent to the base circles of the gears ( $\mathrm{fig}$. 2). In this model, both mesh stiffness and damping values are assumed to be constant, and tooth separation is not considered, since the gears are assumed to be constant, and heavily loaded. By choosing the $y$ axis on the pressure line and the $x$ axis perpendicular to the pressure $l i n e$, the transverse vibrations in the $x$ direction are uncoupled from both the torsional vibrations and the transverse vibrations in the $y$ direction. For the system of figure 2 , the mesh forces in the $y$ direction can be written as

$$
\begin{gathered}
w_{1}=c_{m}\left(\dot{y}_{p}+r_{p} \dot{\theta}_{1}+e_{p} \omega_{p} \cos \theta_{1}-\dot{y}_{g}-r_{g} \dot{\theta}_{2}-e_{g} \omega_{g} \cos \theta_{2}-e_{t} N_{p} \omega_{p} \cos \left(N_{p} \theta_{1}\right)\right) \\
+k_{m}\left(y_{p}+r_{p} \theta_{1}+e_{p} \sin \theta_{1}-y_{g}-r_{g} \theta_{2}-e_{g} \sin \theta_{2}-e_{t} \sin \left(N_{p} \theta_{2}\right)\right) \\
w_{2}=-w_{1}
\end{gathered}
$$

where $w_{1}$ and $w_{2}$ are mesh forces in the $y_{p}$ and $y_{g}$ directions at the driving and driven gear locations, respectively; $c_{m}$ and $k_{m}$ are mesh damping and mesh stiffness values; $e_{p}$ and $e_{g}$ are geometric eccentricities of driving and driven gears; and $r_{p}$ and $r_{g}$ are base circle radil of the driving and driven gears. The angles $\theta_{1}$ and $\theta_{2}$ are the total angular rotations of the driving and driven gears, respectively, and are equal to

$$
\begin{aligned}
& \theta_{1}=\theta_{p}+\omega_{p} t \\
& \theta_{2}=\theta_{g}+\omega_{g} t
\end{aligned}
$$

where $\theta_{\mathrm{p}}$ and $\theta_{\mathrm{g}}$ are the alternating parts of rotations and $\omega_{\mathrm{p}}$ and $\omega_{\mathrm{g}}$ are the spin speeds of the driving and driven shafts, respectively. The displacement, et, which may be considered to be a transmission error excitation, is applied at the mesh polnt. This displacement is usually taken to be sinusoidal at the gear mesh frequency but could include higher harmonics of this frequency. Ozguven and Houser (1988b) have shown that it is possible 
to simulate the varlable mesh stiffness, approximately, by using a constant mesh stiffness with a displacement excitation representing loaded static transmission error. Thus, by choosing $e_{t}$ as the amplitude of the loaded static transmission error, the effect of variable mesh stiffness can be approximately considered in the model.

Mesh forces also cause moments about dynamic centers of the gears which are equal to

$$
\begin{aligned}
& M_{1}=w_{1}\left(r_{p}+e_{p} \cos \theta_{1}\right) \\
& M_{2}=w_{2}\left(r_{g}+e_{g} \cos \theta_{2}\right)
\end{aligned}
$$

Here, the initial angular positions of geometric eccentricities are taken to be zero. The mesh stiffness and damping matrices and the force vector of the system due to gear errors and unbalances can be obtained by writing the force transmitted as the summation of the average transmitted force (static load), $F_{s}$, and a fluctuating component, and then neglecting high order terms following the substitution of equations (1) and (2) into equations (5) and $(6)$. By defining the degrees of freedom of the system at which the coupling effect appears, as

$$
\left\{q_{1}\right\}=\left[\begin{array}{llll}
y_{p} & \theta_{p} & y_{g} & \theta_{g}
\end{array}\right]^{\top}
$$

the additional mesh stiffness matrix which causes the coupling effect and corresponds to $\left\{q_{1}\right\}$ can be obtalned from equations $(1),(2),(5)$, and (6) to be

$$
\left[k_{m}\right]=\left[\begin{array}{cccc}
k_{m} & k_{m} r_{p} & -k_{m} & -k_{m} r \\
k_{m} r_{p} & k_{m} r_{p}^{2} & -k_{m} r_{p} & -k_{m} r_{p} r^{2} \\
-k_{m} & -k_{m} r_{p} & k_{m} & k_{m}^{r} g \\
-k_{m}^{r} g & -k_{m} r_{p}^{r} g & k_{m} r^{r} g & k_{m} r^{2}
\end{array}\right]
$$

Similarly, the mesh damping matrix can be found to be

$$
\left[c_{m}\right]=\left[\begin{array}{cccc}
c_{m} & c_{m} r_{p} & -c_{m} & -c_{m}{ }^{r} g \\
c_{m}{ }^{r} p & c_{m} r_{p}^{2} & -c_{m} r_{p} & -c_{m}{ }^{r} p^{r} g \\
-c_{m} & -c_{m}{ }^{r} p & c_{m} & c_{m}^{r} g \\
-c_{m}{ }^{r} g & -c_{m}{ }^{r} p^{r} g & c_{m}^{r} g & c_{m} r^{2}
\end{array}\right]
$$

The other degrees of freedom defined at nodes $p$ and $g$ have not been included in the vector $\left\{q_{1}\right\}$ since elements of $[\mathrm{Km}]$ and $\left[\mathrm{C}_{\mathrm{m}}\right]$ corresponding to these degrees of freedom are all zero. For the degrees of freedom expressed as

$$
\left\{q_{2}\right\}=\left[\begin{array}{llllll}
y_{p} & x_{p} & \theta_{p} & y_{g} & x_{g} & \theta_{g}
\end{array}\right]^{\top}
$$


the force vector due to runout, transmission errors and mass unbalances are given by

$$
\{F\}=\left[\begin{array}{c}
U_{p} \omega_{p}^{2} \sin \omega_{p} t+F_{1} \\
U_{p} \omega_{p}^{2} \cos \omega_{p} t \\
-F_{s} e_{p} \cos \omega_{p} t+r_{p} F_{1} \\
U_{g} \omega_{g}^{2} \sin \omega_{g} t-F_{1} \\
U_{g} \omega_{g}^{2} \cos \omega_{g} t \\
F_{s} e_{g} \cos \omega_{g} t-r_{g} F_{1}
\end{array}\right]
$$

where

$$
\begin{aligned}
F_{1}=c_{m}\left(e_{g} \omega_{g} \cos \omega_{g} t-e_{p} \omega_{p}\right. & \left.\cos \omega_{p} t+e_{t} N_{p} \omega_{p} \cos \left(N_{p} \omega_{p} t\right)\right) \\
& +k_{m}\left(e_{g} \sin \omega_{g} t-e_{p} \sin \omega_{p} t+e_{t} \sin \left(N_{p} \omega_{p} t\right)\right)
\end{aligned}
$$

Adding the mesh stiffness matrix given by equation ( 8 ) to the stiffness matrix of the uncoupled rotor system yields the total stiffness matrix of the system. The natural frequencies $\omega_{r}$ and the mode shapes $\left\{u^{r}\right\}$ of the system can be determined by solving the eigenvalue problem by considering the homogeneous part of the system equation. In the solution, the sequential Threshold Jacobi method was used.

\section{Forced Response}

The total force vector can be obtained by combining the force vector due to the mass unbalances of the shafts and the other disks and the force vector due to the mass unbalances of gears and gear errors as given in equation (11). This vector is the sum of harmonic components with three different frequencles $\omega_{p}, \omega_{g}$, and $\left(N_{p} \omega_{p}\right)$, and has the following general form:

$$
\begin{aligned}
\left\{F_{t}\right\}=\left\{F_{s p}\right\} \sin \omega_{p} t+\left\{F_{c p}\right\} \cos \omega_{p} t & +\left\{F_{s g}\right\} \sin \omega_{g} t+\left\{F_{c g}\right\} \cos \omega_{g} t \\
& +\left\{F_{s m}\right\} \sin \left(N_{p} \omega_{p} t\right)+\left\{F_{c m}\right\} \cos \left(N_{p} \omega_{p} t\right)
\end{aligned}
$$

The total response of the system to this excitation can be written as

$$
\begin{aligned}
\{q\}= & {\left[\alpha_{p}\right]\left\{F_{s p}\right\} \sin \omega_{p} t+\left[\alpha_{p}\right]\left\{F_{c p}\right\} \cos \omega_{p} t+\left[\alpha_{g}\right]\left\{F_{s g}\right\} \sin \omega_{g} t } \\
& +\left[\alpha_{g}\right]\left\{F_{c g}\right\} \cos \omega_{g} t+\left[\alpha_{m}\right]\left\{F_{s m}\right\} \sin \left(N_{p} \omega_{p} t\right)+\left[\alpha_{m}\right]\left\{F_{c m}\right\} \cos \left(N_{p} \omega_{p} t\right)
\end{aligned}
$$

where $\left[\alpha_{p}\right],\left[\alpha_{g}\right]$ and $\left[\alpha_{m}\right]$ are the receptance matrices corresponding to the exciting frequencies, $\omega_{p}, \omega_{g}$, and $\left(N_{p} \omega_{p}\right)$, respectively, and givan by 


$$
\begin{aligned}
{\left[\alpha_{p}\right] } & =\sum_{s=1}^{n} \frac{\left\{\Phi^{s}\right\}\left\{\Phi^{s}\right\}^{T}}{\omega_{s}^{2}-\omega_{p}^{2}+i \omega_{p} c_{s}} \\
{\left[\alpha_{g}\right] } & =\sum_{s=1}^{n} \frac{\left\{\Phi^{s}\right\}\left\{\Phi^{s}\right\}^{T}}{\omega_{s}^{2}-\omega_{g}^{2}+i \omega_{g} c_{s}} \\
{\left[\alpha_{m}\right] } & =\sum_{s=1}^{n} \frac{\left\{\Phi^{s}\right\}\left\{\Phi^{s}\right\}}{\omega_{s}^{2}-N_{p}^{2} \omega_{p}^{2}+i N_{p} \omega_{p} c_{s}}
\end{aligned}
$$

Here, $\left\{\Phi^{5}\right\}$ represents the $s^{\text {th }}$ mass matrix normalized modal vector, $n$ is the total number of the degrees of freedom of the system, 1 is the unit imaginary number, and $c_{s}$ is the sth modal damping value given by the $s^{\text {th }}$ diagonal element of the transformed damping matrix [C] where

$$
[\bar{C}]=[\Phi]^{\top}[C][\Phi]
$$

and where $[\Phi]$ is the normalized modal matrix. In this approach it is assumed that the damping matrix is the proportional type, which is usually not correct for such systems. When the damping is not proportional, the transformed

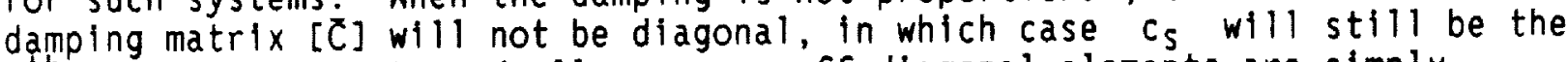
$s^{\text {th }}$ diagonal element, and all nonzero, off-diagonal elements are simply ignored when using the classical, uncoupled-mode superposition me thod. Another approach for including damping in the dynamic analysis of such systems would be to assume a modal damping, $\zeta_{s}$, for each mode and then replace $c_{s}$ in equations (14) and (15) by $2 \zeta_{\mathrm{s}} \omega_{\mathrm{s}}$. However, it is belleved that using the actual values for damping, when they are known, and using an approximate solution technique may give more realistic results than assuming a modal damping value for each mode.

\section{APPLICATIONS AND NUMERICAL RESULTS}

\section{Comparison With An Experimental Study}

As the first application, the experimental setup of Iida et al. (1980) was modeled ( $f \mathrm{~g} . \mathrm{l}$ ). The gear system conslsts of two geared rotors: one is connected to a motor with a mass moment of Inertia of $\mathrm{J}_{m}$, and the other is connected to a load with a mass moment of inertia of $J_{d}$. Each shaft is supported by a pair of ball bearings. The parameters of the system are listed in table I. The gears with inertias $I_{p}$ and $I_{g}$ are both mounted on the middle of the shafts of lengths $L_{1}$ and $L_{2}$ and diameters $d_{1}$ and $d_{2}$. respectively. The driving and driven gears' respective base circle radif are $r_{p}$ and $r_{g}$ and their masses are $m_{p}$ and $m_{g}$. In their study, Ilda et al. (9980) did not specify the length of the second shaft, $L_{2}$, and the properties of bearlings and couplings. Instead, they gave the total torsional stiffness 
values for driving and driven parts of the system and a total transverse stiffness value for the second shaft. Therefore, we have estimated the length of the second shaft, $L_{2}$, and the torsional stiffness of the first coupling, $\mathrm{K}_{\mathrm{tcl}}$, in our model so that the total values given by Iida et al. (1980) were obtained. The forced vibration response due to a geometrlc eccentricity eg and a mass unbalance $U_{g}$ is shown in figure 3 , along with the experimental results of Ilda et al. (1980). Since no information is given about the damping values of the system, a modal damping of 0.02 has been used at each mode in the computations. As seen in figure 3 , predictions from the analytical model show good correlation with the experimental results.

Response Due to Geometric Eccentricities, Mass Unbalances, Static Transmission Error and Mesh Stiffness Variation

As a second application, the system used by Neriya et al. (1985) was studied to investigate the effects of geometric eccentricities and mass unbalances of the gears on the forced response of the system. The natural frequencles, mode shapes, and the responses at both gear locations due to geometric eccentricities and mass unbalances of gears obtalned were almost identical to those documented by Neriya. The results of this analysis have not been included in this study since gear eccentricities and unbalances excite the system at the shaft rotational frequencies as was shown in the first example. The contribution of such low-frequency excitations on the generated gear noise is usually negligible when compared with that of high-frequency excitations caused by transmission errors and mesh stiffness varlations.

On the other hand, the system shown in figure 4 has been modeled to obtain the dynamic mesh force due to a harmonic displacement excitation of amplitude $e_{t}$ and frequency $\left(N_{p} \omega_{p}\right)$ representing the mesh stiffness variation. Dimensions of the rotors shown given in figure 4 and other system parameters are listed in table II. The bearings are assumed to be identical, and geometric eccentricities and mass unbalances for gears are assumed to be zero, so that the only excitation causing a forced response is the harmonic displacement excitation defined. Since the displacement input approximates the loaded static transmission error, the value of $e_{t}$ was taken as the amplitude of the loaded static transmission error. Figure 5 shows the varlation with rotational speed of the ratio of dynamic to static mesh load for three different bearing compliances. The first two small peaks of figure 5 correspond to torsional modes of shafts, and the third peak corresponds to the coupled lateral/torsional mode governed by the gear mesh.

As shown in figure 5, when the bearing stiffnesses are decreased, the dynamic force also decreases considerably because of a resulting decrease in the relative angular rotations of the two gears. Although the displacements in the $y$ direction increase slightly, they do not appreciably affect the dynamic force. In this example, a mesh damping corresponding to a modal damping of 0.1 in the mode of gear mesh has been used. This was the value used by several investigators for the same problem. 


\section{The Effect of Bearing Compliances on Gear Dynamics}

A parametric study of the system shown in figure 6 was performed. The effects of bearing compliances on the natural frequencles and the forced response of the system to the harmonic excitation representing the static transmission error and the mesh stiffness variation were studied. The system parameters are given in table III. The natural frequencies and the physical descriptions of the corresponding modes for a value of bearing stiffnesses $k_{x x}=k_{y y}=1.0 \times 10^{9} \mathrm{~N} / \mathrm{m}$ are presented in table IV. The forced response at the pinion focation in both the transverse (pressure line) and rotational directions, and dynamic mesh forces are plotted in figures 7 to 9 . Figures 7 and 8 show that the system has peak responses only at two natural frequencies in the range analyzed. Mode shapes corresponding to these two natural

frequencles are presented in figure 10. When the free vibration

characteristics of these two modes is investigated in detail, it is seen that the dynamic coupling between the transverse and torsional vibrations at these two modes are dominant. It is al so seen that dynamic loads are high at only the second one of these two modes as shown in figure 9 . The reason for this is that the transverse and torsional vibrations for the second mode considered apply at the same direction at the mesh point. This results in large relative deflections at the mesh point which implies that this mode is governed by gear mesh. It is also seen from these figures that lowering the values of bearing stiffnesses causes a decrease in both the values of the natural frequencles and the amplitudes of the peak responses and dynamic loads.

Figure 11 shows the varlation of these natural frequencies with bearing stiffnesses for three shaft compllances: (1) long shafts (low stiffness) with dimensions given in figure 6 , (2) moderately compliant shafts with half the length of the long shafts, (3) very short (stiff) shafts. The shaft and the bearings supporting the gears can be thought of as two springs connected in series. When one of these components is very stiff compared with the other, its effect on the overall dynamic behavlor becomes negligible. When the mode shapes for these two modes are examined for the case of short shafts and stiff bearings, the first of these two modes becomes purely torsional, while the lateral vibrations become more important in the second mode. As shown in figure $11(a)$, since the mode considered becomes purely torsional in the case of short shafts and stiff bearings, the value of this natural frequency does not change as bearing stiffnesses exceed a limiting value. For the other mode considered, the natural frequency becomes very high when a short bearing is used with a very stiff bearing, since the lateral vibrations are more dominant than torsional vibrations in this mode $(f i g . \mid 1(b))$. Similarly, when the shafts are flexible enough, the effect of bearing stiffnesses on the natural frequency becomes negligibie above a limiting value of bearing stiffness.

\section{CONCLUSION}

A finite-element model was developed to investigate the dynamic behavior of geared rotor systems. In the analysis, transverse and torsional vibrations of the shafts and the transverse vibrations of the bearings have been considered. Effects such as transverse and rotary inertia an axial load, were included in the model, and internal damping of the shafts was included only in the damping matrix. The gear mesh was modeled by a pair of rigid disks connected by a spring and a damper with constant values that represent average 
mesh values. Tooth separation was not considered. The model developed finds the natural frequencles, corresponding mode shapes, and forced response of the system to mass unbalances and to the geometric eccentriclties of gears and transmission error excltations. Although a constant mesh stiffness was assumed, the self-excitation effect of a real gear mesh was included in the analysis by using a displacement excitation representing the static transmission error.

Although it may be justified to solve nonlinear equations in simpler models, for large models such as the ones used in this study, avoiding nonlinearities and transient solutions saves considerable computation time. In the example problems only the first harmonic of the static transmission error was considered and good predictions were obtained.

Finally, it has been shown that the bearing compliances can greatly affect the dynamics of geared systems. Decreasing the stiffness values of bearings beyond a certain value lowers the natural frequency governed by the gear mesh considerably. However, in the case of compliant shafts, when the bearing stiffnesses are above a certain value, the natural frequency corresponding to the gear mesh does not change considerably by increasing bearing stiffnesses. On the other hand, it has been seen that the amplitudes of dynamic to static load ratio and the deflections at the torsional and transverse directions are decreased by using bearings with higher compliances, which shows that the bearing compliance may also affect the dynamic tooth load, depending upon the relative compliances of the other elements in the system.

\section{REFERENCES}

1. Bagci, C.; and Rjavenkateswaran, S.K.: Critical Speed and Modal Analyses of Rotating Machinery Using Spatial Finite-Line Element Method.

Proceedings of the Fifth International Modal Analysis Conference, D.J. Demichele, ed., Syracuse Univ. Press, Syracuse, New York, 1987, pp. 1708-1717.

2. Daws, J.W.: An Analytical Investigation of Three Dimensional Vibration in Gear-Couple Rotor Systems. Ph.D. Thesis, Virginia Polytechnic Institute and State University, VA, 1979.

3. Hagiwara, N.; Ida, M.; and Kikuchi, K.: Forced Vibration of a Pinion-Gear System Supported on Journal Bearings. Proceedings of International Symposium of Gearing and Power Transmissions. (Tokyo), N. Kikaigakkai, ed., Japan Society of Mechanical Engineers, Tokyo, 1981, pp. 85-90.

4. Hamad, B.M.; and Selreg. A.: Simulation of Whirl Interaction in Pinion-Gear Systems Supported on $011 \mathrm{Film}$ Bearings. J. Eng. Power, vol. 102 , no. 2,1980 , pp. 508-510.

5. Iida, H., et al.: Coupled Torsional-Flexural Vibration of a Shaft in a Geared System of Rotors (Ist Report). Bull. Japan. Soc. Mech. Eng., vol. 23, no. 186, Dec. 1980, pp. $2111-2117$. 
6. Ilda, H.; and Tamura, A.: Coupled Torsional-Flexural Vibration of a Shaft in a Geared System. International Conference on Vibration in Rotating Machinery, 3rd, Mechanical Engineering Publications, London, 1984 ,

pp. $67-72$.

7. Iida, H.; Tamura, A.; and Oonishi, M.: Coupled Dynamic Characteristics of a Counter Shaft in a Gear Train System. Bull. Japan. Soc. Mech. Eng., vol. 28, 1985, pp. 2694-2698.

8. Ilda, H.; Tamura, A.; and Yamamoto, H.: Dynamic Characteristics of a Gear Train System with Softiy Supported Shafts. Bull. Japan. Soc. Mech. Eng., vol. 29, 1986, pp. 1811-1816.

9. Iwatsubo, T.; Arli, S.; and Kawai, R.: Coupled Lateral-Torsional Vibrations of Rotor Systems Trained by Gears (1. Analys is by Transfer Matrix Method), Bul1. Japan. Soc. Mech. Eng., vol. 27, 1984, pp. $271-277$.

10. Iwatsubo, T.; Aril, S.; and Kawal, R.: Coupled Lateral Torsional Vibration of a Geared Rotor System. International Conference on Vibrations in Rotating Machinery, 3rd, Mechanical Engineering Publications, London, 1984, pp. 59-66.

11. Lund, J.W.: Critical Speeds, Stablitity and Response of a Geared Train of Rotors. J. Mech. Des., vol. 100, no. 3, 1978, pp. 535-538.

12. MItche11, L.D.; and David, J.W.: Proposed Solution Methodology for the Dynamicaily Coupled Nonlinear Geared Rotor Mechanics Equation. ASME, Paper 85-DET-90, Sept. 1983.

13. Mitchell, L.D.; and Mellen, D.M.: Torsional-Lateral Couple in a Geared High-Speed Rotor System. J. Mech. Eng., vol. 97, no. 12, 1975, p. 95.

14. Nelson, H.D.: A Finite Rotating Shaft Element Using Timoshenko Beam Theory. J. Mech. Des., vol. 102, no. 4, 1980, pp. 793-803.

15. Nelson, H.D.; and McVaugh, J.M.: The Dynamics of Rotor-Bearing Systems Using Finite Elements. J. Eng. Ind., vol. 98, no. 2, 1976, pp. 593-600.

16. Neriya, S.V.; Bhat, R.B.; and Sankar, T.S.: Effect of Coupled TorslonalFlexural Vibration of a Geared Shaft System on Dynamic Tooth Load. Shock vib. Bull., vol. 54, pt. 3, 1984, pp. 67-75.

17. Nerlya, S.V.; Bhat, R.B.; and Sankar, T.S.: Coupled Torsional Flexural Vibration of a Geared Shaft System Using Finite Element Method. Shock Vib. Bull., vol. 55, pt. 3, 1985, pp. 13-25.

18. Ozguven, H.N.; and Houser, D.R.: Mathematical Models Used in Gear Dynamics. J. Sound Vib., vol. 121, Mar. 1988, pp. 383-411.

19. Ozguven, H.N.; and Houser, D.R.: Dynamic Analysis of High Speed Gears by Using Loaded Static Transmission Error. J. Sound Vib., vol. 125, Aug. 1988, pp. 71-83. 
20. Ozguven, H.N.; and Ozkan, Z.L.: Whirl Speeds and Unbalance Response of Multibearing Rotors Using Finite Elements. ASME Paper 83-DET-89, Sept. 1983.

21. Ozkan, Z.L.: Whirl Speeds and Unbalance Responses of Rotating Shafts Using Finite Elements. M.S. Thesis, The Middle East Technical University, Ankara, Turkey, 1983.

22. Zorzi, E.S.; and Nelson, H.D.: Finite Element Simulation of Rotor-Bearing Systems with Internal Damping. J. Eng. Power, vol. 99, no. 1., 1977. pp. $71-76$. 
TABLE I. - PARAMETERS OF THE GEAR SYSTEM OF FIGURE 1

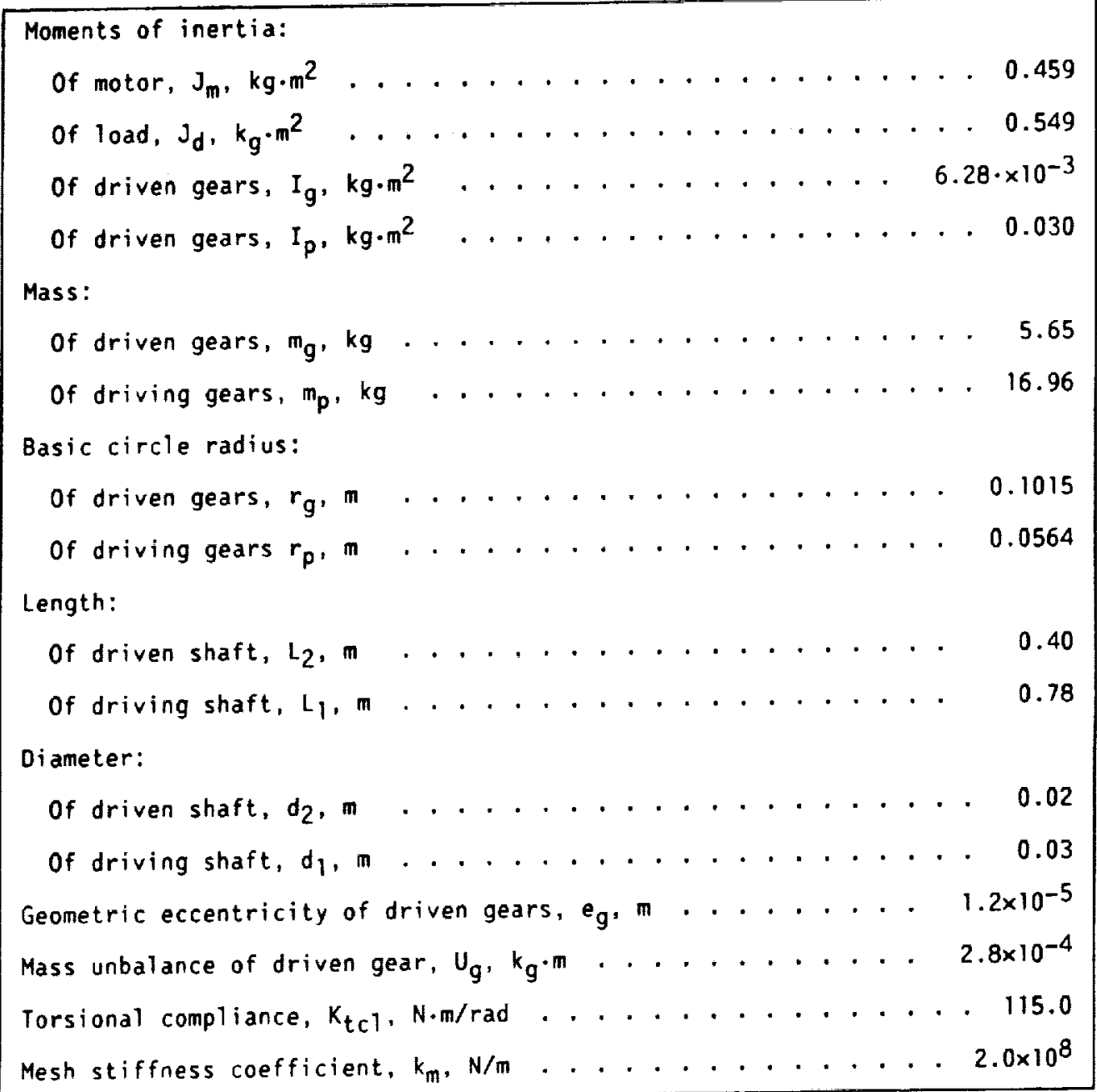


TABLE II. - PARAMETERS OF THE GEAR SYSTEM OF FIGURE 4

[Variable hearing stiffness of values.]

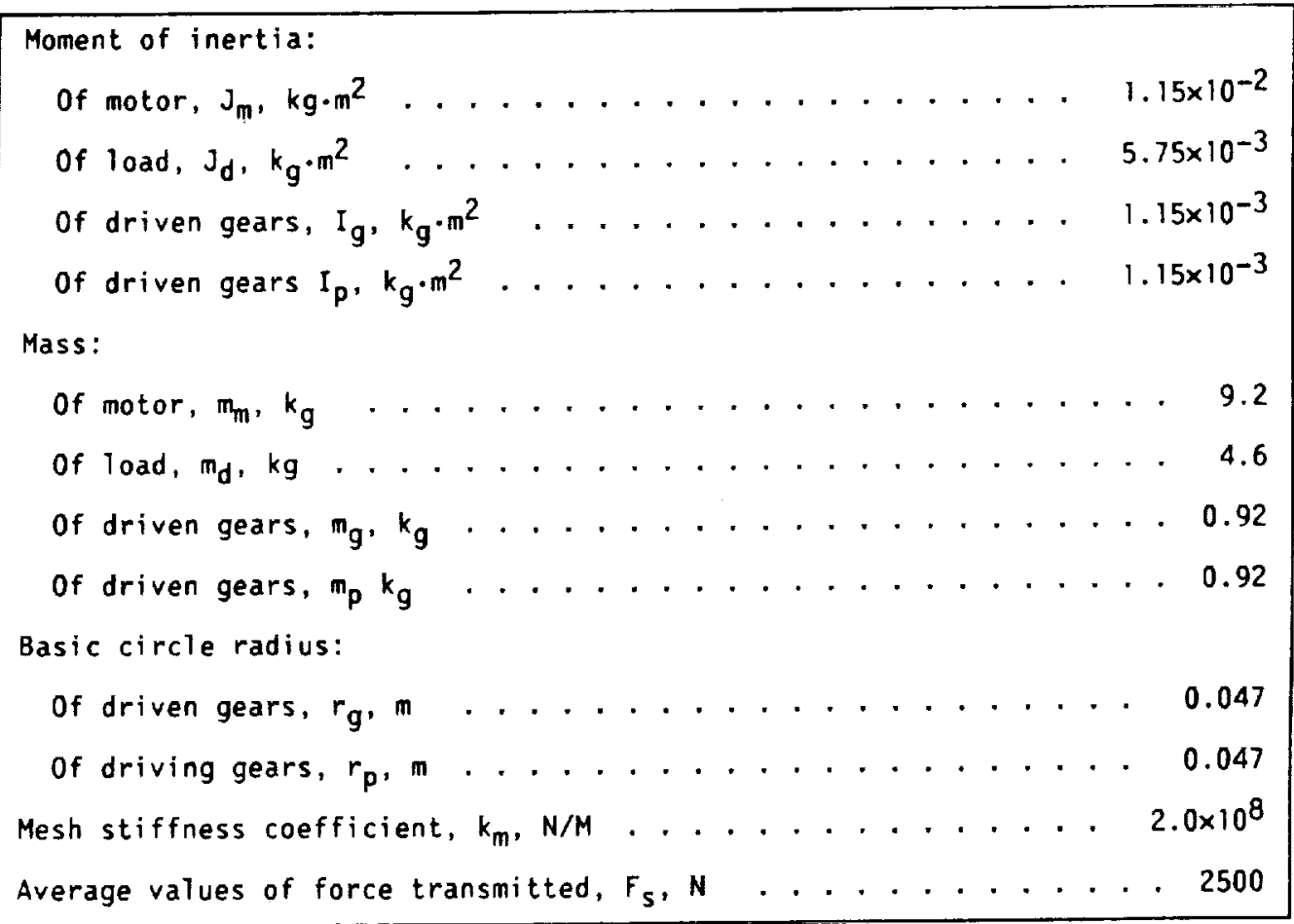


Moment of inertia:

of driven gears, $\mathrm{I}_{\mathrm{g}}, \mathrm{kg}_{\mathrm{g}} \mathrm{m}^{2}$. . . . . . . . . . . . . 0.0018

of driving gears, $I_{p}, k_{g} \cdot \mathrm{m}^{2}$. . . . . . . . . . . . . 0.0018 Mass:

of driven gears, $m_{g}, k_{g}$. . . . . . . . . . . . . . . . 1.84

of driving gears, $m_{p}, k_{g}$. . . . . . . . . . . . . . . . . 1.84

Base circle radius:

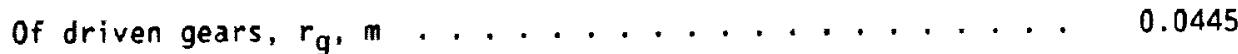

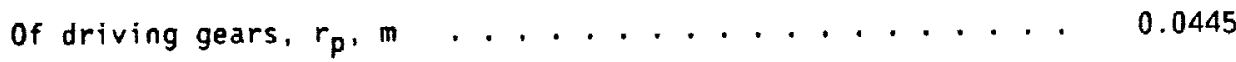

Amplitude of the harmonic excitation, $e_{t}, m \ldots . . . . .9 .3 \times 10^{-6}$

Mesh stiffness coefficient, $\mathrm{k}_{\mathrm{m}}, \mathrm{N} / \mathrm{m} . . . . . . . . .1 .0 \times 10^{8}$

Tooth numbers of driving gear, $\mathrm{N}_{\mathrm{p}}$. . . . . . . . . . . . . . . . . 28

TABLE IV. - FIRST 14 NATURAL FREQUENCIES OF THE SYSTEM OF

FIGURE 6 FOR THE CASE OF $k_{x x} / k_{m}=10$

\begin{tabular}{|c|c|}
\hline $\begin{array}{c}\text { Natural frequency, } \\
\mathrm{Hz}\end{array}$ & Corresponding mode \\
\hline 0 & Torsional rigid body \\
\hline 581 & Transverse, torsional \\
\hline 687 & Transverse, $x$ dir., driving shaft \\
\hline 689 & Transverse, y dir. \\
\hline 691 & Transverse, $x$ dir., driven shaft \\
\hline 2524 & Transverse, torsional \\
\hline 3387 & Transverse, y dir. \\
\hline 3387 & Transverse, $x$ dir., driving shaft \\
\hline 3421 & Transverse, $x$ dir., driven shaft \\
\hline 3421 & Transverse, y dir. \\
\hline 6447 & Torsional, driving shaft \\
\hline 6539 & Torsional, driven shaft \\
\hline 6831 & Transverse, $x$ dir., driving shaft \\
\hline 6840 & Transverse, y dir. \\
\hline
\end{tabular}




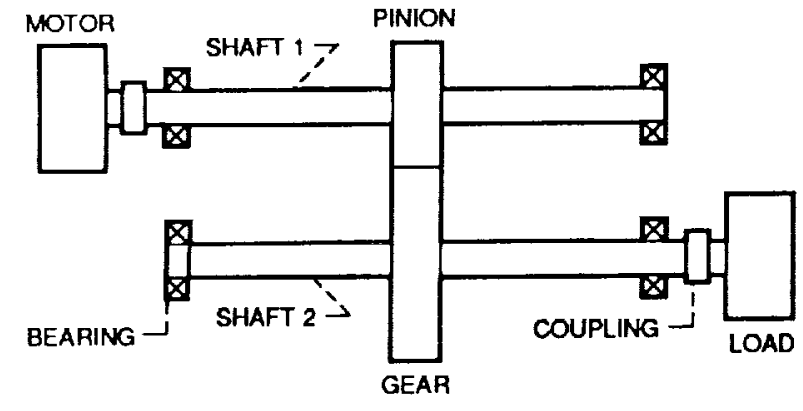

Figure 1. - A typical gear-rotor system.

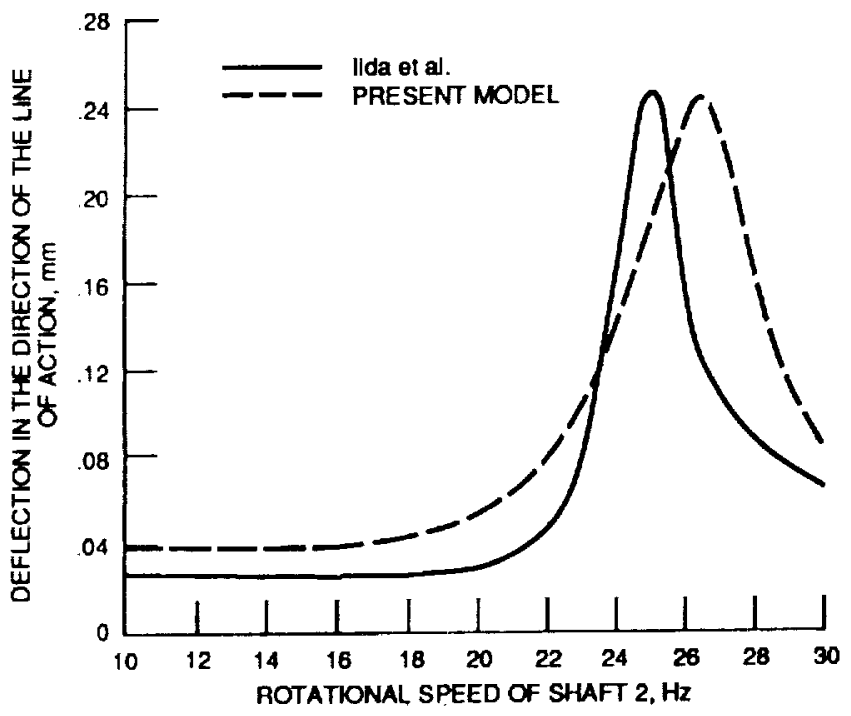

Figure 3. - Comparison of the theoretical values of the dynamic deflection of the dilven gear In the pressure llne direction with the experimental results given by llda ol al. (1980).

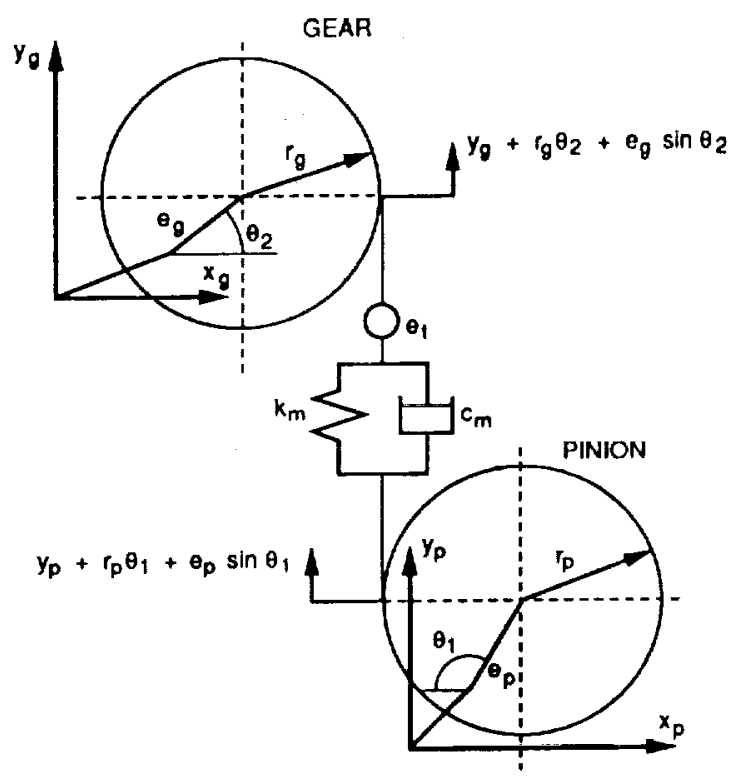

Figure 2. - Modeling of a gear mesh.

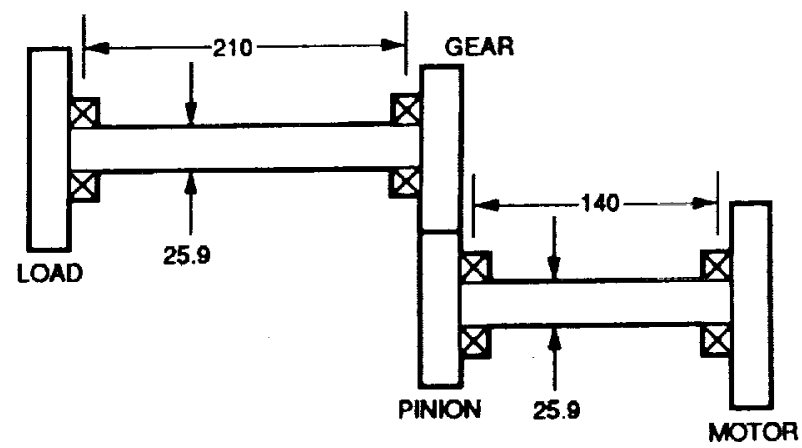

Figure 4. - The system of the second example. (Dimensions are in millimeters. 


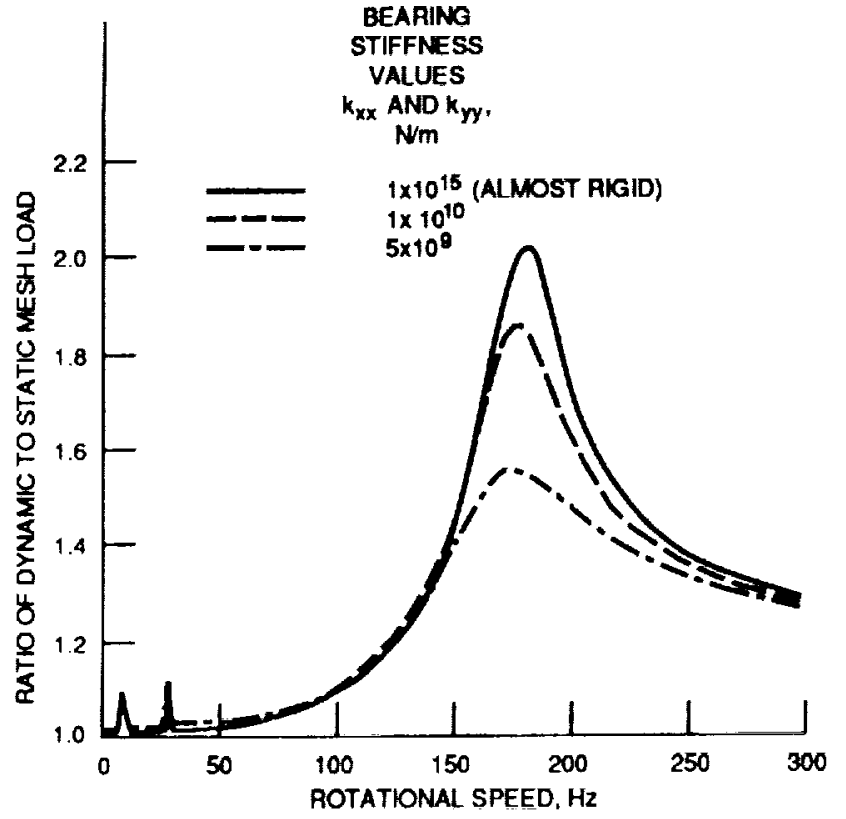

Figure 5. - Varlation of dynamlc to static load ratio with frequency for three different bearing compliances.

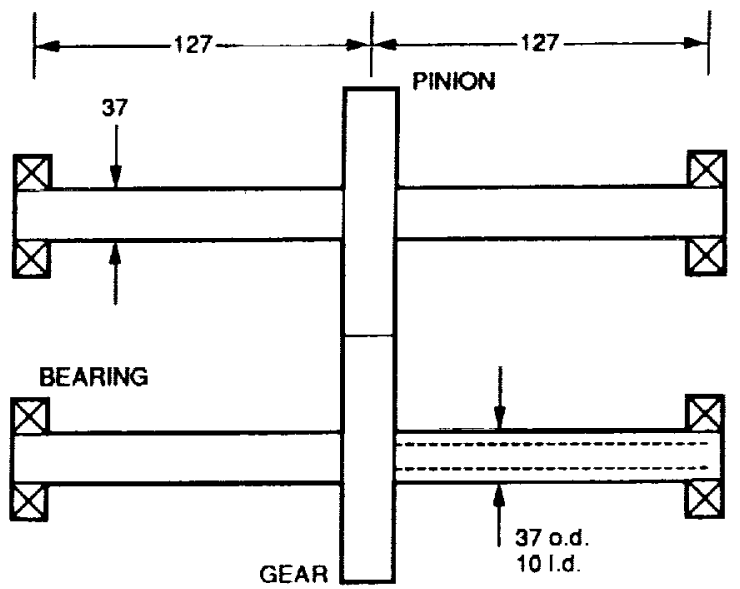

Figure 6. - The system analyzed as a third example (Dimensions are In millimelers.)

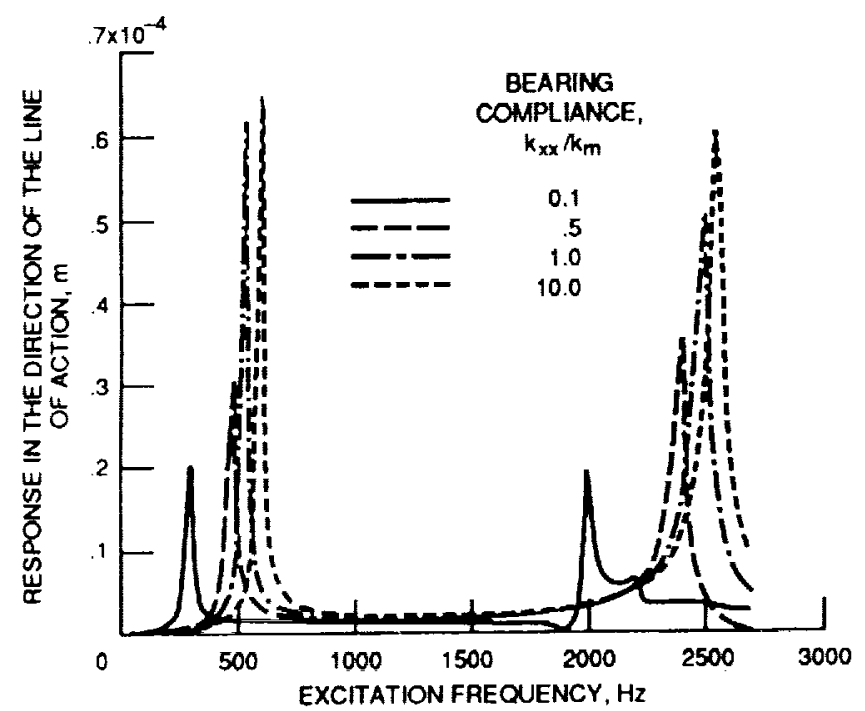

Figure 7. - Forced response of the system shown in houre 6 to the displacement excltation at the direction of presuure line (at pinion location) for four different bearing compliances.

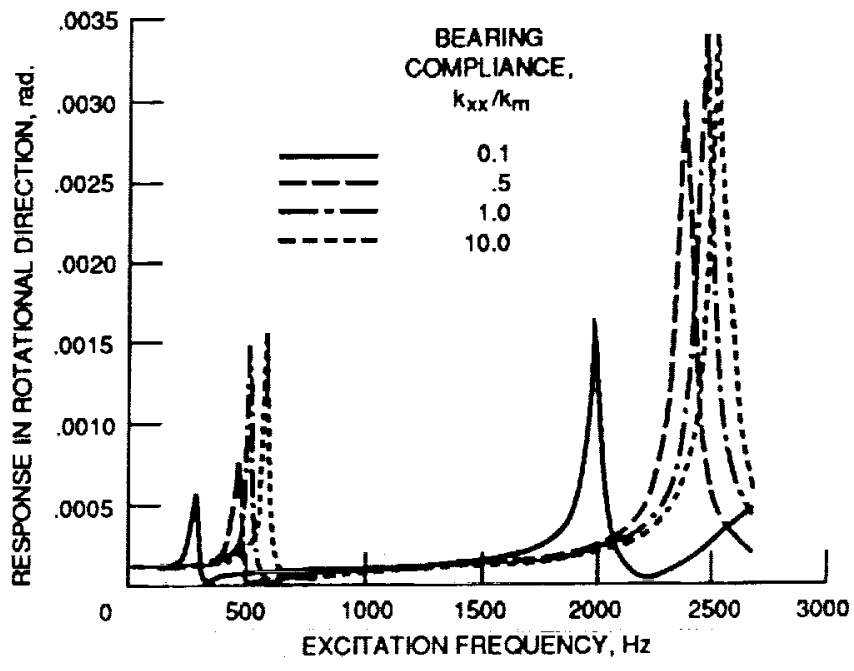

Floure B. - Forced response of system shown in figure 6 to the displacement exctation at the torsional direction (at pinion location) for four different bearing complicances. 


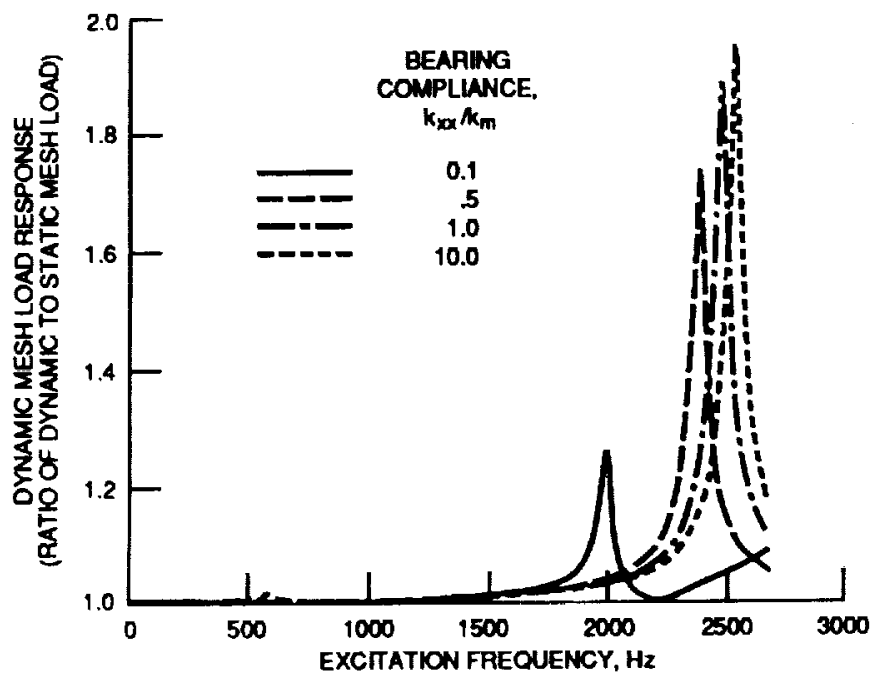

Figure 9. - Dynamic to static load ralios for system show in figure 6 dus to the displacement excitation for four difierent bearing compliances.

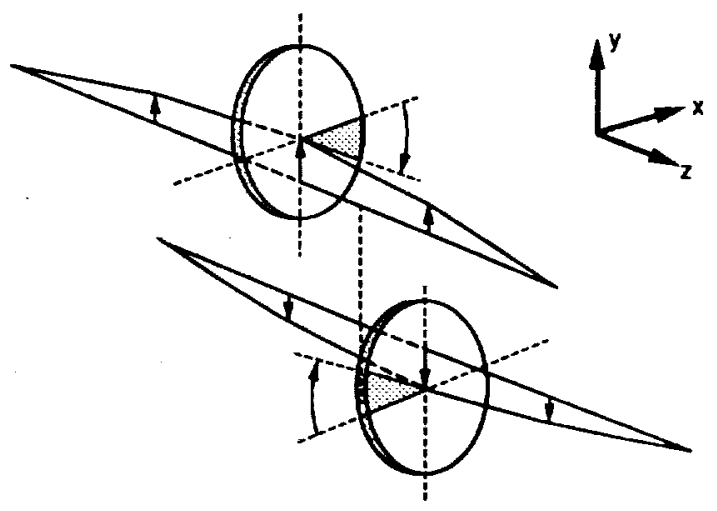

(a) Natural frequency, $581 \mathrm{~Hz}$.

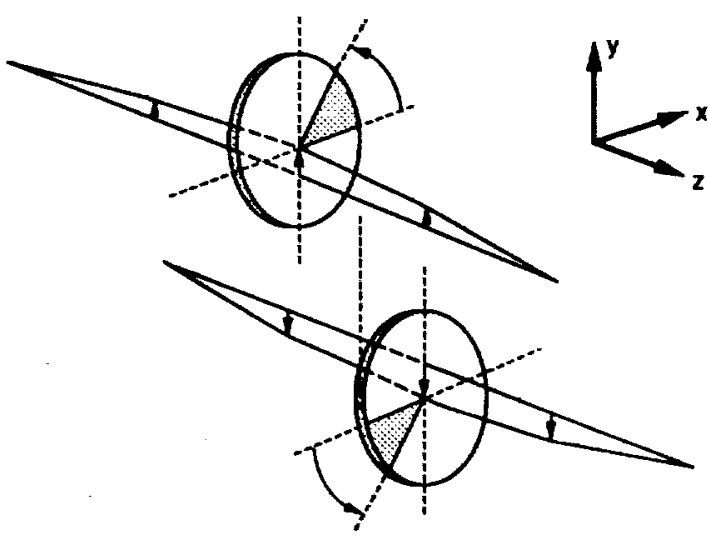

(b) Natural frequency, $2524 \mathrm{~Hz}$.

Figure 10. - Mode shapes corresponding to natural frequencies at which the system shown in foure 6 hes peak responses. 


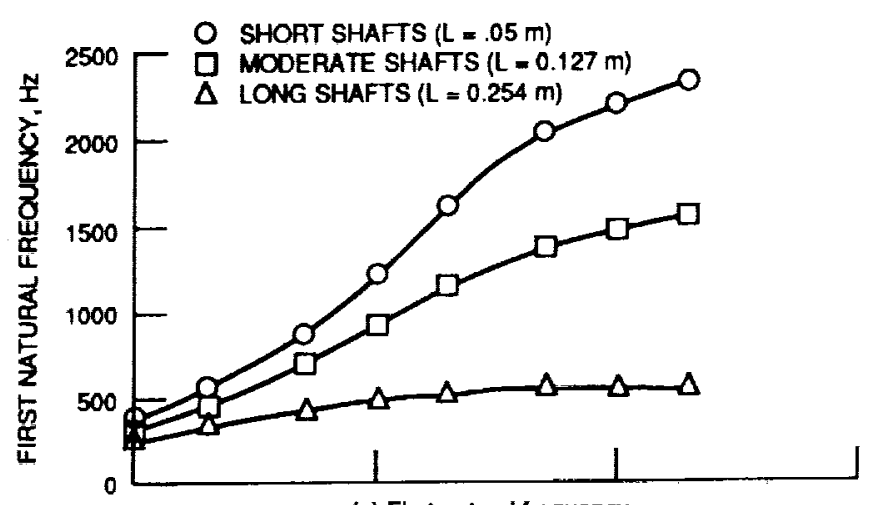

(a) First natural trequency.

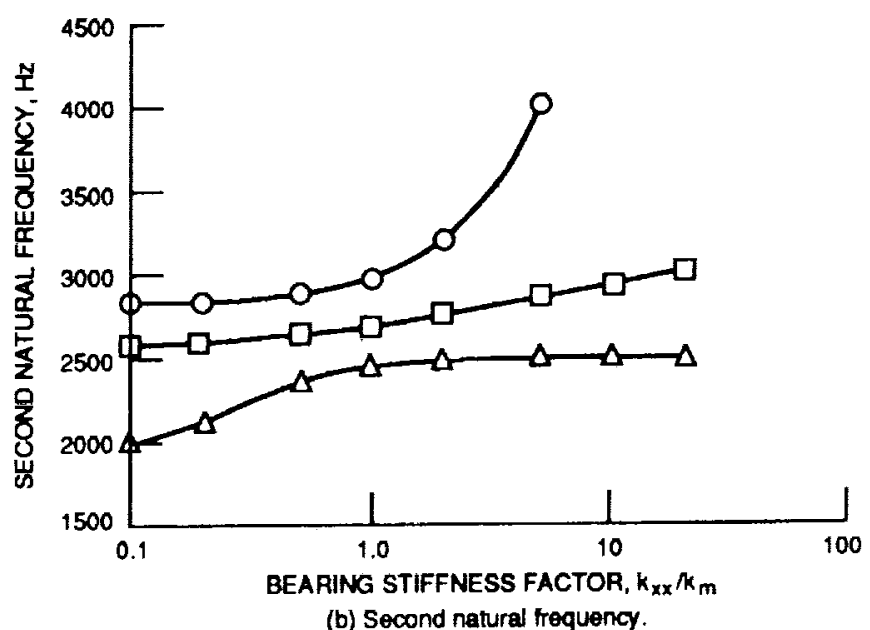

Figure 11. - Varlation of natural trequency considered with bearing stiffthesses for three difierent shaft compliances. 


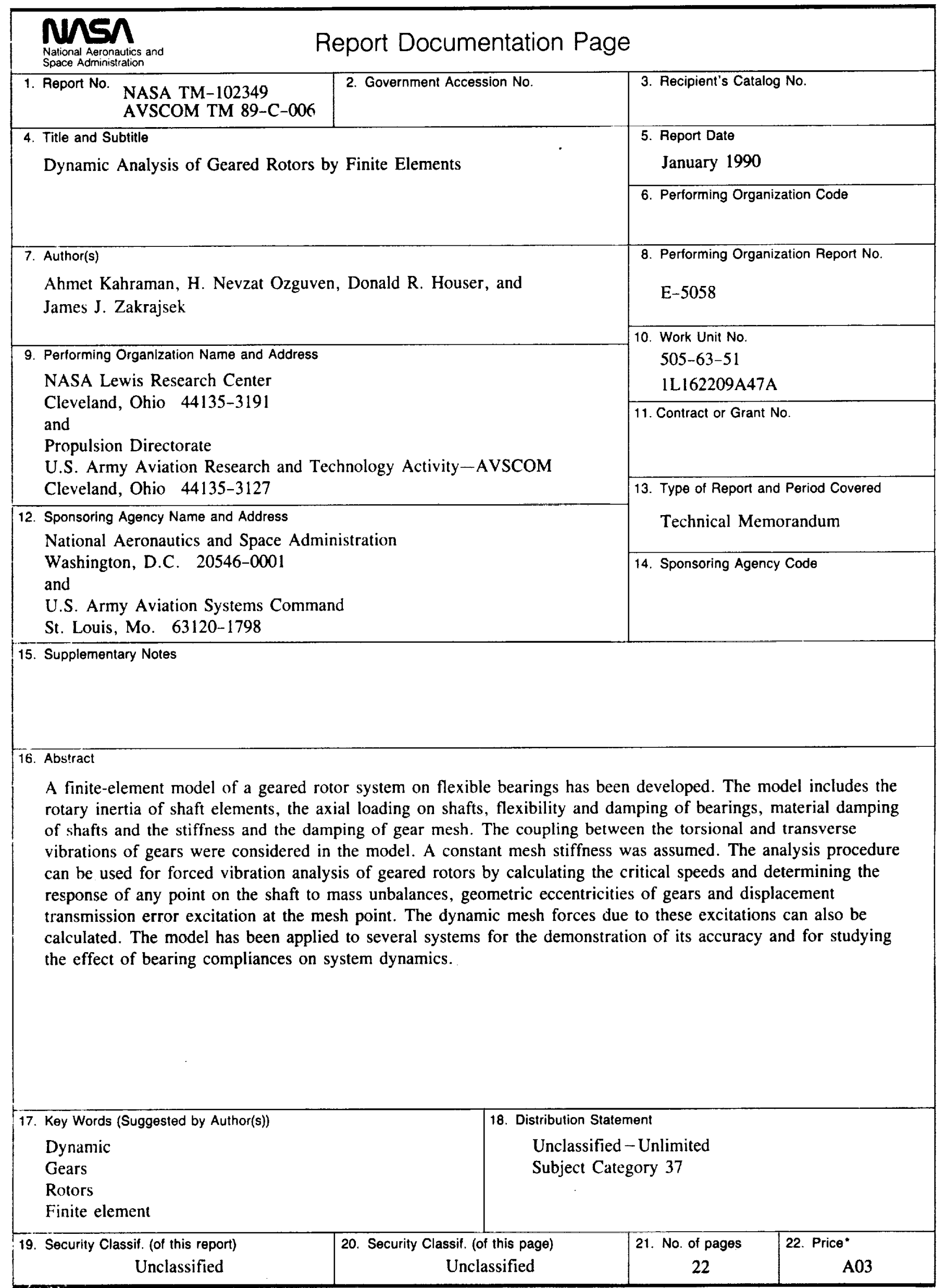


